\title{
EXPERIÊNCIA E NARRAÇÃO: REFLEXÕES A PARTIR DO DOCUMENTÁRIO DE DANÇA-TEATRO SONHOS EM MOVIMENTO
}

\author{
Jeferson de Oliveira Cabral \\ Mestre em Artes Cênicas pela Universidade Federal do Rio Grande do Sul \\ Email: grandeje@gmail.com \\ Vera Lúcia Bertoni dos Santos \\ Professora Associada do Departamento de Arte Dramática e Pesquisadora vinculada ao Programa de \\ Pós-Graduação em Artes Cênicas da Universidade Federal do Rio Grande do Sul \\ Email: bertonica@gmail.com
}

$\mathrm{O}$ artigo enfoca o ato de narrar e suas relações com o compartilhamento de experiências potencialmente transformadoras do íntimo dos sujeitos que as vivenciam. A escrita, de cunho experimental, traz a interpretação de narrativas de jovens estudantes do Ensino Médio que tiveram seus caminhos transformados a partir de uma experiência artístico formativa em dança-teatro, proporcionada por uma remontagem do espetáculo da coreógrafa alemã Pina Bausch e registrada no documentário Sonhos em Movimento, das cineastas Anne Linsen e Rainer Hoffmann (2010). Os autores que inspiram as reflexões são Jorge Larossa (2015), Timothy O'leary (2008) e Walter Benjamin (1993). O propósito do trabalho é conectar as noções de narração e de experiência com relatos vivos dos jovens, que expõem sua potência em forma de narrativa no documentário.

\section{Palavras-chave}

Dança-Teatro. Narração. Experiência. Artes Cênicas.
The article focuses on the act of narrating and its relations with the sharing of potentially transformative experiences in the inner of people who experience it. The experimental writing brings the interpretation of narratives of young high school students whose paths have been transformed by a formative artistic experience in dance-theater, provided by a recreation of a play by the German choreographer Pina Bausch and registered in the documentary Dancing Dreams by Anne Linsen and Rainer Hoffmann (2010). The authors who inspire the reflections are Jorge Larossa (2015), Timothy O'leary (2008) and Walter Benjamin (1993). The purpose of the text is to connect the notions of narration and experience with living stories of young people that expose its power as narrative in the documentary.

Keywords

Dance Theater. Narrating. Experience. Scenic Arts. 


\section{Sobre experiência e narração}

Neste texto, a problematização da noção de experiência faz-se a partir de articulações entre estudos de teóricos do campo da filosofia, como o espanhol Jorge Larrosa e o francês Michel Foucault, este, sob interpretação do pesquisador norte-americano Timothy O'leary. $\mathrm{O}$ olhar a tais referentes busca tecer considerações a respeito do ato de narrar experiências, tendo por base a contribuição do ensaísta e filósofo alemão, Walter Benjamin. Nesse sentido, considera-se a narração um ato posterior ao acontecimento denominado experiência, tornada possível somente após a reflexão perante o experienciado.

Para Larrosa (2011), a experiência está ligada a ações fora de nosso controle, momentos que nos atravessam no encontro com o outro, como em uma improvisação teatral, durante a qual o ator desconhece qual será a reação de seu companheiro de cena perante seus gestos, movimentos ou falas.

\begin{abstract}
A experiência supõe, em primeiro lugar, um acontecimento, ou dito de outro modo, o passar de algo que não sou eu. E "algo que não sou eu" significa também algo que não depende de mim, que não é uma projeção de mim mesmo, que não é resultado de minhas palavras, nem de minhas ideias, nem de minhas representações, nem de meus sentimentos, nem de meus projetos, nem de minhas intenções, que não depende nem do meu saber, nem de meu poder, nem de minha vontade (Larrosa, 2011, p. 5)
\end{abstract}

A ideia da experiência surgir do encontro leva a pensar que o ser humano não é protagonista daquilo que pode arrebatá-lo e colocá-lo em estado distinto do cotidiano. Como em momentos em que nos deixamos levar pelo entusiasmo ao ouvirmos certa canção em língua estrangeira, cujo significado não compreendemos, ao nos depararmos com um ipê roxo florido, ou com pedras seculares no chão de uma cidade andaluza. Situações independentes do nosso controle de afetação, nas quais o afeto por elas provocado não pode ser explicado pela simples lógica de fatos.

Larrosa (2015) lança-se à tarefa de desmistificar o uso excessivo e, ao mesmo tempo, o descaso com a palavra "experiência". A expressão excesso remete a algo que se tem ou se faz demais, e tem como exemplo o entendimento de experiência ser aquilo que "nos passa". Nesse caso, é preciso abertura para que não nos limitemos somente a essa resposta, pois a experiência, por mais teorizada que seja, caracteriza também aquilo que é pele, que acontece no íntimo de cada ser. Nesse sentido, temos a reflexão do próprio Larrosa (2015, p. 43): "Pessoalmente, tentei soar a palavra experiência perto da palavra vida, ou melhor, de um modo mais preciso, perto da palavra existência. A experiência seria o modo de habitar o mundo de um ser que existe [...]". Com isso, o autor ressalta a sutileza de não conceituar a palavra e sim deixá-la fluir.

Outra importante referência à noção de experiência é encontrada nos escritos de O'leary (2008) sobre a obra de Foucault. Conforme o autor, Foucault compreende a experiência como algo extremo, uma situação limite, ainda não vivida e sem precedentes, caracterizada por ações alheias ao sujeito.

Para Foucault, o sujeito é um ser de experiências transformadoras. A partir do acontecimento experiencial, o sujeito move-se em direção a algo que não era e não lograria ser, caso isso não acontecesse, ação que constituiria uma situação limítrofe, de mudança. A trans- 
formação surge a partir de "uma experiência que nos arranca de nós mesmos e nos deixa diferente daquilo que éramos antes" (Foucault apud O'leary, 2008, p. 2).

A vivência de experiências que nos reformulam e que nos dão pistas à compreensão de mudanças em trajetórias de vida significa, na leitura de O'leary sobre Foucault, uma abertura de portas significante de uma virada de rumo do ser. A mudança de rumo é tida como uma ação posterior ao acontecimento da experiência, pois acontece a partir da saída do sujeito de si a fim de refletir sobre o que lhe aconteceu e sua volta, que possivelmente permite a mudança.

Outra ação implicada à experiência é o ato de compartilhar os seus frutos com outras pessoas, transformando-os em narrativa. Nesse sentido, Benjamin (1993) propõe discussões no campo da escrita literária, expondo aspectos como o crescimento e importância do romance em detrimento da forma narrativa e as características de um narrador e do ato de narrar. A partir dessas colocações, a tomada do autor como referência justifica-se não pela relação de conflito que ele traça entre diferentes vertentes literárias, mas pelo diálogo que ele estabelece entre o ato de narrar e as experiências cotidianas.

Para Benjamin, narrar é compartilhar mais que a própria história, é presenteá-la ao outro. A relação entre pessoas, estabelecida através da narração, expande o ambiente de troca. $A$ questão do cuidado com o outro é enfatizada pelo autor em oposição a um ambiente em que as pessoas já não se importam em compartilhar as pequenas coisas que lhes arrebatam no passar dos dias. Seus escritos apontam a importância do jogo entre quem conta e quem escuta, valorizando a experiência narrada para outros. Segundo Benjamin (1993, p. 197-198)

Uma experiência quase cotidiana nos impõe a exigência dessa distância e desse ângulo de observação. É a experiência de que a arte de narrar está em vias de extinção. São cada vez mais raras as pessoas que sabem narrar devidamente. [...]. É como se estivéssemos privados de uma faculdade que nos parecia segura e inalienável: a faculdade de intercambiar experiências.

O autor faz uma pertinente crítica às formas de sociabilidade do seu tempo. Para ele, os seres humanos construíram um ambiente em que trocam informações sem qualquer tipo de envolvimento. Numa realidade em que "nada está a serviço da narrativa e sim da informação" (Benjamin, 1993, p. 203), a experiência da narração conduz os sujeitos a ultrapassar o simples ato de informar. Nesse contexto, o ato de narrar, de compartilhar experiências, pode significar o encontro com a memória, "a mais épica de todas as faculdades" (Benjamin, 1993, p. 210). Quando narramos, não estamos somente informando algo a alguém, mas sim provocando uma troca de afetações. A provocação das lembranças perante a expressão a outros daquilo que nos move funciona como um ato sensível de partilha que pulveriza as relações burocráticas que estabelecemos na sucessão dos dias.

Os estudos do filósofo George Agamben acerca da política e da estética na contemporaneidade expõem também a problemática da transmissão de histórias no contexto atual. Para o autor, "o contemporâneo deixou incapaz o ser de fazer e transmitir experiências" (Agamben, 2005, p. 21). Ou seja, assim como Benjamin, Agamben parece entender que sofremos pela falta de comunicação sobre acontecimentos cotidianos. 
O encontro das ideias desses autores, tecidas aqui de forma experimental, constitui um ponto de partida para vislumbrar que o acontecimento de experiências é potencializado pelo compartilhamento através da narração. Nesse sentido, compreende-se o campo da arte como um espaço de compartilhamento sensível, propulsor de mudanças na realidade de artistas e espectadores, pois os transporta (ou possibilita que se abra uma porta) para o lúdico da existência.

\section{A narração como escrita de si e como experiência}

Como exemplo desse tipo de processo com potencial altamente transformador têm-se uma série de depoimentos fornecidos por jovens estudantes do Ensino Médio da cidade de Wuppertal, na Alemanha, e captadas pelas lentes dirigidas por Anne Linsen e Rainer Hoffmann, no documentário Sonhos em Movimento (2010), aqui interpretados como narração de experiências artístico formativas em dança-teatro.

As experiências foram proporcionadas pela bailarina e coreógrafa alemã Pina Bausch (1940-2009), diretora do grupo de dança-teatro Tanztheater Wuppertal e duas ensaiadoras que colaboraram com o processo.

Numa rápida caracterização, o documentário Sonhos em Movimento consiste num registro audiovisual que leva seu espectador até a cidade de Wuppertal, para contar a história de um grupo de jovens que decide se aventurar em uma experiência artístico formativa que resulta num processo comovente de entrega e aprendizagem sobre si e sobre o outro, mediado pela arte da dança-teatro e pelo envolvi- mento no espetáculo Kontakthof.

Kontakthof, do alemão, "pátio de contatos", ou, "lugar de contatos", aborda o tema da incompletude relacional: os afetos e relações humanas que nunca se completam; encontros que se chocam ao vento, mas que seguem seu rumo desprezando o contato, às vezes amoroso. O espetáculo, criado na sua versão original pelos bailarinos da Tanztheater Wuppertal, em 1978, mostra, de forma sutil, a violência que as pessoas cometem umas em relação às outras e a fugacidade de encontros superficiais (Climenhaga, 2009, p. 50). E a remontagem com jovens acontece no ano de 2008, reunindo um elenco composto por jovens estudantes com idades entre de quatorze a dezessete anos. A criação ocorreu ao longo de um ano e, após esse período, cumpriu temporada em alguns países da Europa. As pesquisadoras brasileiras Marina Medeiros e Sayonara Pereira (2012, p. 4) referem-se à repercussão do trabalho de Bausch na cidade:

Wuppertal é, basicamente, uma cidade industrial, com um cenário cultural restrito e muitos de seus moradores, até os dias atuais, não conhecem o trabalho de Bausch [...]. Porém com as experiências de Kontakthof Bausch movimentou três gerações de sua cidade. Desenvolveu um trabalho com a terceira idade e com os jovens e, inevitavelmente, envolveu vários adultos, uma vez que seus filhos e/ou pais, conhecidos, ou parentes, se tornaram protagonistas da peça, e desta maneira, a cidade passa a "fazer parte da Companhia".

A intenção aqui é expor diferentes modos de como os jovens bailarinos iniciantes apropriaram-se da experiência e transformaram em narração o que viveram no processo de ensaios em dança-teatro, criando formas próprias de compartilhar algo que, na sua pers- 
pectiva, Ihes mostrara novas possibilidades de existir e conviver com o outro. Nessa medida, serão apontadas algumas das mudanças mencionadas pelo elenco juvenil perante suas percepções sobre si por meio da atuação no espetáculo.

Os depoimentos dos jovens sobre o processo vivenciado trazem reflexões ligadas a uma visão mais imediatista do acontecimento, pois os depoimentos foram colhidos ao mesmo tempo em que ensaiavam, sem espaço temporal para que o aprendizado fosse decantado. Contudo, suas reflexões indicam aspectos potentes revelados a partir da experiência com dança-teatro, tais como a desinibição na vida cotidiana e a possibilidade de virem a ser mais sociáveis e apreciadores de arte.

Ao refletir sobre os ensaios, um jovem explicita a compreensão de suas experiências: "Tenho de admitir que teve impacto em mim, porque eu costumava ser uma pessoa tímida e agora quando fazemos esta peça abrimo-nos, após algum tempo. Fazendo teatro você acaba se soltando" (Sonhos, 1.20') ${ }^{1}$.

Observe-se que esse depoimento revela um comportamento comum aos sujeitos da sala de aula das escolas brasileiras de Ensino Médio: a postura fechada, retraída, como tentativa do jovem de mostrar controle de seu envolvimento até que se sinta confiante, seguro para abrir-se perante o grupo. Tal atitude tende a significar barreiras à relação entre professor e aluno e alunos entre si. Todavia, a partir dos estudos de Foucault, é possível relacionar a vivência desses jovens com o processo de ensaios a uma experiência limite. Considera-se que suas vidas tenham sido transformadas a par-

1 Molde usado para a minutagem de depoimentos do documentário: entre parênteses, a hora completa, seguida de ponto final; o minuto, seguido de um apóstrofo; e o segundo, seguido de dois apóstrofos (ex: 1.23'43"). tir do momento em que deixaram de participar apenas como aprendizes e foram desafiados a colocarem-se numa atmosfera profissional, plena de compromissos, responsabilidades e exigências. A experiência limite para eles pode ser interpretada como a criação de uma nova realidade de vida, a artística.

Outro depoimento contém palavras que se somam à ideia de transformação através de uma experiência que pode ser considerada limite: "Eu no início não fazia ideia de onde estava. Ainda estava armado, só fazia o que queria. Mas já mudei por causa da Pina Bausch. Estou muito orgulhoso de mim próprio" (Sonhos, 38'58"). O depoimento parece misturar o pensar sobre o que o jovem era anteriormente à experiência e o que passou a ser, devido à fricção entre seu próprio querer e o querer do outro. Observa-se que a experiência com dança-teatro possibilitou a ele despir-se de pré-julgamentos sobre os outros e sobre si mesmo.

A timidez pode ser compreendida como um comportamento construído socialmente, através de conceitos pré-estabelecidos sobre o que é "correto", "normal" (e, logo, aceito pela sociedade em geral), e sobre o que deve ser evitado, ou coibido em espaços de convívio. $\mathrm{E}$ a arte pode ser pensada como um intervalo, um "respiro" a ser experimentado, capaz de potencializar o sujeito para reflexões não feitas diariamente. Assim, são postos em xeque muitos preconceitos em relação à arte e suas possibilidades, como, por exemplo: o de que a arte não é um bem para todos os indivíduos, pois demanda condições prévias e implica altos custos; o de que nem todos os indivíduos podem aprender a dançar, ou a atuar, por não possuírem corpos ideais, aptidões, ou talentos inatos; e tantos outros boicotes senso comum. 
Um jovem do elenco de Bausch refere-se a esse aspecto:

Pensava que dançar não era para mim. Mas no dia anterior, vi o filme "Bily Eliot", vi que o personagem ficou muito famoso e pensei que poderia arrepender-me se não fosse até lá. $E$ depois fui lá, e gostei muito, é sensacional. Agora, sinto-me sortudo por tê-lo feito (Sonhos, 05'35').

Na nossa sociedade, especialmente no meio escolar, a timidez costuma ser vista como falta de confiança em si, acarretando muitas dificuldades de relacionamento entre pares; e entre os jovens participantes do documentário a visão não era diferente. Mas seus depoimentos revelam que o fazer artístico lhes possibilitou expandir horizontes e apropriarem-se de seus próprios atos, tornando-os mais confiantes e seguros para exporem seus sentimentos perante o grupo. Como diz uma intérprete do espetáculo: "Já não sou tão tímida. Tornei-me muito mais confiante neste tempo" (Sonhos, 1.20'40").

Os depoimentos a seguir evidenciam a relação de aprendizado a partir da experiência dos jovens com Bausch e com as ensaiadoras do espetáculo, e mostram o que ficou da relação afetuosa, por vezes também exigente, construída no espaço de criação de Kontakthof: "Quando tivemos a primeira reunião, me senti tão insegura. Não sabia o que esperar. A primeira conversa na escola foi bastante descontraída, mas depois tudo mudou" (Sonhos, 13'16"). A mudança a qual a jovem se refere parece ter-se dado em função do convívio equilibrado entre descontração e trabalho. Por mais que o ambiente de ensaio fosse repleto de amigos e houvesse espaço para o divertimento, havia um grande desafio a ser enfrentado. Nesse contexto, descontra- ção e disciplina encontram-se e caracterizam uma atmosfera em que o compromisso com o que é produzido torna-se um acordo no fazer artístico. Ou seja, a construção artística dos jovens gerou um envolvimento e um vínculo estreito com os fazeres de uma companhia de dança-teatro. Como expressa outro integrante do processo:

Não fazia ideia do que esperar. Pensei que dançaria um pouco e logo veria como aconteceria. Lá com minha melhor amiga, conheceríamos gente nova, era essa minha ideia, até começarem os ensaios. Então percebemos que era sério (Sonhos, 14'46").

Há também depoimentos de participantes da montagem que relevam suas percepções sobre a experiência de aprendizagem em dança-teatro. Tais relatos abarcam a construção de novos mundos existenciais, como caminhos possíveis, bem como abordam as dificuldades encontradas na composição das cenas: "Acho difícil identificar-me com a obra, porque não foi criada por nós. Tem a ver com questões que a Sra. Bausch colocou a seus bailarinos. Há que senti-lo e eu não o sinto" (Sonhos, 11'41").

Essa narrativa levanta uma problemática importante: participar de um processo cênico desde sua criação e compreender as peculiaridades de uma remontagem, na qual experiências de outros artistas precisam ser ressiginificadas, apropriadas. As premissas de Foucault possibilitam pensar na proposta de sentir o mundo de outras pessoas e de operar uma transformação de quem somos a partir de determinada experiência.

O depoimento da jovem que desempenhou o papel de protagonista do espetáculo parece representar o pensamento de todos os participantes da experiência, pois é nítida a relação 
afetiva construída entre eles e a produção do evento: "Levei algum tempo para dar um abraço apertado na Jo (uma das ensaiadoras) e a confiar nela. Embora nunca sentisse que ela pudesse me enganar, mas levo tempo a ganhar confiança e confidenciar-me com alguém" (Sonhos, 51'50").

Sob essa óptica, fazer arte é confiar no outro, pois dificilmente algo acontece no âmbito individual; mesmo num espetáculo com um só ator em cena, é necessário alguém que o veja de fora, que o ilumine, e que o assista. No campo das Artes Cênicas nada se faz sozinho, pois, em última hipótese, é necessário o espectador, sem o qual a cena não faz sentido, não acontece.

Larrosa (2011) considera que a experiência é algo que não podemos influenciar, pois é gerada através da relação com o mundo, com as outras pessoas que, na interação com nossa existência, transformam momentos de troca em aprendizado. Assim, o ato de confiar é compreendido como inerente à arte. Nessa perspectiva, evidencia-se a instância poética de Sonhos em Movimento. As reflexões sobre experiência aqui trazidas representam uma interpretação conferida à relação dos jovens do documentário com a dança-teatro. Relação que era distinta no processo de criação de Bausch com sua companhia, que criava a dramaturgia de seus espetáculos a partir das experiências de vida do elenco. Essa forma de criação cênica gera outro tipo de contato com a experiência; uma relação em que o artista constrói e reconstrói sua experiência ao dançar.

O documentário possibilita ao espectador compreender a forma de como se constituiu a criação de um espetáculo com jovens que nunca haviam passado por um processo for- mativo em Artes Cênicas. Suas narrativas sobre o processo pelo qual passaram são tão vivas no registro, que motivaram a elaboração deste artigo, que se faz por atravessamentos ligados ao pensar de Benjamin (1993, p. 201) sobre a função narrativa: "O narrador retira da experiência o que ele conta [...]. E a incorpora as coisas narradas às experiências de seus ouvintes".

Desse modo, reflete-se sobre o mergulho dos jovens na arte e sobre a potência do encontro sensível entre eles e a arte, que aconteceu por meio das narrativas de suas experiências com as propostas de dança-teatro de Bausch. E essa afetação fortifica o pensamento de que os processos de criação de Bausch primam, também, pelo objetivo de proporcionar a não artistas estarem em cena e problematizarem a sociedade e suas experiências por meio da dança. Tal premissa é um forte aspecto filosófico na dança-teatro e viabiliza um olhar pedagógico a ela, pois em espaços onde se propicia autoconhecimento, propicia-se a reflexão filosófica.

\section{Referências}

AGAMBEN, Giorgio. Infância e história. Ensaio sobre a destruição da experiência. In: Infância e história. Destruição da experiência e origem da história. Trad. Henrique Burigo. Belo Horizonte: Ed. UFMG, 2005, p. 19-78.

BENJAMIN, Walter. O narrador. Considerações sobre a obra de Nikolai Leskov. In: Magia e Técnica, Arte e Política. [Obras Escolhidas]. Trad. Sergio Paulo Rouanet. São Paulo: Brasiliense, 1993, p. 197-221. 
CLIMENHAGA, Royd. Pina Bausch. New York: Routledge, 2009.

LAROSSA, Jorge. A experiência e suas linguagens. In:_. Tremores. Escritos sobre experiência. Trad. Cristina Antunes e João Wanderley Geraldi. Belo Horizonte: Autêntica, 2015, p. 35-56.

MEDEIROS, Marina Milito de. PEREIRA, Sayonara. Pina Bausch, de referência mundial ao trabalho social - Kontakthof através das gerações. Estúdio artistas sobre outras obras, v. 3, $\mathrm{n}^{\circ}$ 5, 2012.

Experiência e alteridade em educação. Reflexão e Ação, vol.9, n.2, 2011, p.04-27.

O'LEARY, Timothy. Foucault, Experience, Literature. Foucault Studies, n5, p. 5-25, jan. 2008.

SONHOS EM MOVIMENTO. Direção: Anne Linsel e Rainer Hoffman: Imovision, Berlim, 2010, 1.29', (89min).

Recebido: 20/04/2017 Aprovado: 08/07/2017 